\title{
Everolimus for the treatment of refractory seizures associated with tuberous sclerosis complex (TSC): current perspectives
}

This article was published in the following Dove Press journal:

Therapeutics and Clinical Risk Management

Iris E Overwater'

André B Rietman ${ }^{2}$

Agnies $M$ van Eeghen ${ }^{3}$

Marie Claire $\mathrm{Y}$ de $\mathrm{Wit}^{\mathrm{I}}$

'Department of Pediatric Neurology and ENCORE Expertise Center, Erasmus MC,

Rotterdam, the Netherlands;

${ }^{2}$ Department of Child and Adolescent Psychiatry/Psychology and ENCORE

Expertise Center, Erasmus MC,

Rotterdam, the Netherlands; ${ }^{3}$ Heeren

Loo Care Group and ENCORE Expertise

Center, Erasmus MC, Rotterdam, the

Netherlands
Correspondence: Marie Claire Y de Wit Department of Pediatric Neurology and ENCORE Expertise Center, Erasmus MC, PO Box 2040, Rotterdam, CA 3000, the Netherlands

Tel +3 II0 703634I

$\mathrm{Fax}+3 \quad 1107036345$

Email m.c.y.dewit@erasmusmc.nl

\begin{abstract}
Up to $90 \%$ of patients with tuberous sclerosis complex (TSC) have epilepsy, and in over half of patients seizure control cannot be achieved by regular antiepileptic drugs. The underlying problem is mTOR hyperactivation due to loss of function of the TSC proteins. Treatment with everolimus, an mTOR inhibitor, has been shown to be of great benefit to TSC patients, both in reducing tumor growth and as a treatment for intractable epilepsy. Up to $40 \%$ of TSC patients with intractable epilepsy show a clinically relevant seizure response to everolimus. It has not yet fully lived up to its promise as a disease-modifying drug, however, as half of TSC patients with intractable epilepsy do not show a clinically relevant seizure frequency reduction. There is no evidence yet of a positive effect on the cognitive and neuropsychiatric deficits in TSC patients. In preclinical studies, mTOR inhibition can rescue abnormal neuronal migration and synapse formation that is caused by mTOR hyperactivation. These studies show a critical time window that suggests that mTOR inhibition may be most beneficial in young children. The trials done so far have not studied treatment in children under 2 years of age, although case series suggest that the safety profile is similar to that in older children. Further studies into the optimal time window, dosing schedules and possibly combination with other drugs may further improve the benefit of everolimus for TSC patients.
\end{abstract}

Keywords: mTOR, epileptogenesis, epilepsy

\section{Tuberous sclerosis complex}

Tuberous Sclerosis complex (TSC) is a rare autosomal dominant disorder that is characterized by the development of multiple hamartomas. These are typically seen in brain, kidney, skin, heart, liver and lungs, although other organs can be affected. There is a large variability in the severity of TSC between patients; however, the neurological and psychiatric features are often the most important clinical problems. These include intellectual disability, autism, anxiety and attention problems, summarized in the term TSC-Associated-Neuropsychiatric-Disorders (TAND), but epilepsy is often the most important determinant of quality of life. ${ }^{1}$ Up to $90 \%$ of TSC patients develop epilepsy, and over half of the patients with TSC and epilepsy have seizures refractory to anti-epileptic drugs.

Hyperactivation of the mTOR (mechanistic target of rapamycin) pathway due to loss of function of the TSC proteins is thought to be the cause of both the focal cortical dysplasia and the intractable epilepsy in TSC. Hyperactivation of mTOR in neuronal precursors during prenatal brain development leads to abnormal migration 
and differentiation of affected neurons, resulting in giant cells, dysmorphic neurons, abnormal lamination and interrupted migration. Clusters of these abnormal neurons can be seen on magnetic resonance imaging (MRI) imaging as tubers and radial migration lines. During further brain development, mTOR hyperactivation disturbs neuronal arborization and spine maturation. TSC patients with germline mutations are haploinsufficient for either the TSC1 or TSC2 gene in all their cells. Second hit mutations result in extreme mTOR hyperactivation and are implicated in the development of benign tumors associated with TSC. The giant cells in the tubers are also affected by a second hit.

\section{Treatment of epilepsy with $\mathbf{m T O R}$ inhibitors}

Historically, epilepsy in the context of TSC was treated as any other focal epilepsy following the ILAE (International League against epilepsy) guidelines. The elucidation of the function of the TSC1 and TSC2 genes, and availability of mTOR inhibitors, quickly led to hope for a treatment directly aimed at the underlying dysfunction of the affected cells. For epilepsy, this implied a treatment directed at epileptogenesis, instead of symptomatic treatment of seizures, and possibly treatment with a disease-modifying drug. Everolimus and sirolimus, both mTOR-inhibiting drugs, were shown to be effective in the treatment of TSCrelated renal angiomyolipoma and subependymal giant cell astrocytoma in clinical trials. ${ }^{2,3}$ Preclinical research in animals models seemed to support the hypothesis that mTOR inhition could also rescue epilepsy. ${ }^{4,5}$ Several studies in TSC patients showed a reduction in seizure frequency due to mTOR inhibition. ${ }^{6,7}$ The EXIST-3 trial included 366 patients and showed a 50\% seizure reduction response rate of $15 \%$ with placebo compared with $28 \%$ for low-exposure everolimus and $40 \%$ for high-exposure everolimus. ${ }^{8}$ This was highly significant, and led to the registration of everolimus for the treatment of intractable epilepsy in patients with TSC aged 2 years and older.

\section{Current place of $\mathrm{mTOR}$ inhibitors in the treatment of TSC related epilepsy}

The results of the EXIST-3 trial and the registration of everolimus for the treatment of intractable seizures in TSC have changed the current treatment recommendations (Table 1). In the EXIST-3 trial, patients aged 2 years and older were included, so everolimus cannot yet be recommended for younger patients. As level 1 evidence is only available for the efficacy of everolimus in patients that failed at least 2 anti-epileptic drugs, everolimus is not recommended as a first- or second-line treatment. In the EXIST-3 trial, the seizure response was better in patients with a higher everolimus exposure, indicating a doseresponse relationship. The current dosing recommendations are to aim for a trough level within the range of $5-7 \mathrm{ng} / \mathrm{mL}$ initially and $5-15 \mathrm{ng} / \mathrm{mL}$ in the event of an inadequate clinical response. ${ }^{9}$

\section{Safety profile of $\mathbf{m T O R}$ inhibitors}

The most important side effects of mTOR inhibitors are (apthous) stomatitis and respiratory infections. A recent meta-analysis of safety data showed a high risk of stomatitis (RR 3.20) in patients who received mTOR inhibitors. The incidence of upper respiratory tract infections was high in both treated and untreated patients with a similar risk (RR 1.08). ${ }^{7}$ Treatment-related deaths due to pneumonia or septic shock have been reported. ${ }^{12}$ Recently the extension data for the EXIST-3 registration study were published showing that of 366 participants, $81 \%$ remained on everolimus at 1 year of follow-up and $74 \%$ at 2 years. $13 \%$ discontinued because of adverse events. ${ }^{12}$ This shows that the side effect profile is acceptable for the majority of patients. At the 1-year follow-up mark, $47 \%$ of the patients taking everolimus had a seizure response of $>50 \%$, which is considered clinically relevant. For those patients with limited seizure response, the advantages of everolimus may not outweigh the side effects. On the other hand, mTOR inhibition can also benefit TSC-related symptoms in other organs, such as facial angiofibroma, pulmonary lymphangioleimyomatosis and renal angiomyolipoma.

\section{Questions remaining to be answered}

\section{Does everolimus suppress seizures or} prevent epilepsy? What does that mean for the optimal treatment timing?

An important question remaining is whether everolimus works as an antiseizure medication or antiepileptogenic agent, or as both. If epilepsy is mainly the result of the focal cortical dysplasia that formed during the prenatal phase of neuronal migration and differentiation, then it may be that the epileptogenic process has already been started prenatally, and epilepsy may be inevitable. In TSC 


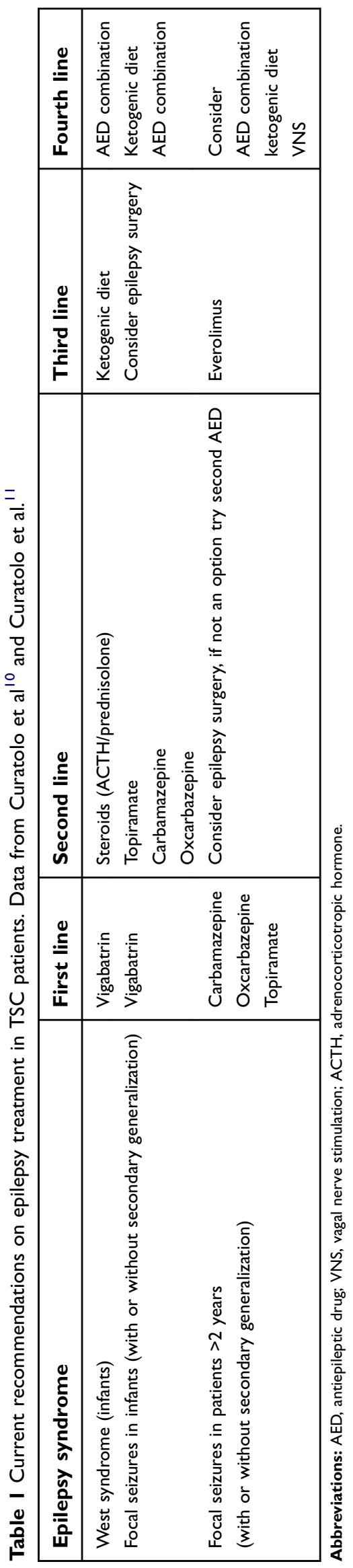

patients, the epileptic focus is often associated with a tuber and removal of such a tuber and the perituberal tissue by epilepsy surgery has a high chance of inducing seizure remission. This may support the hypothesis that the cortical dysplasia is central in epileptogenesis.

However, if dynamic mTOR-dependent processes during development are the main driver of epileptogenesis, inhibition of mTOR hyperactivation may prevent epileptogenesis. Arguments for the latter originate from animal models where acute mTOR hyperactivation in the absence of cortical dysplasia can trigger epilepsy. ${ }^{4}$ In these mice, epilepsy onset can be prevented by rapamycin. Another Tscl animal model shows that there are multiple time windows where mTOR inhibition may work to prevent abnormal brain development. ${ }^{13}$ In these mouse embryos, TSC was induced at different times of brain development. During the prenatal neuronal migration period, rapamycin treatment improved malpositioning of neurons. When administered early postnatally (P1-P13), aberrant arborization of affected neurons was improved and in a later period (P15-P27) spine maturation was partly rescued. After the critical time window for these processes, these abnormalities cannot be rescued by mTOR inhibition. It is yet unclear how to translate these findings to TSC patients, but we know that much of brain maturation and network formation takes place after birth. In humans, neuronal migration takes place before birth, but synaptogenesis continues until approximately 3.5 years of age. This suggests that there may be a (partial) treatment window in humans postnatally. A possible biomarker for the quality of network development is MRI imaging of the white matter using diffusion techniques. Many TSC patients show abnormal white matter integrity, and MRI data from the NCT00411619-trial of everolimus for subependymal giant cell astrocytoma showed that the development of white matter integrity was improved by mTOR inhibition in patients with TSC. ${ }^{14}$ The conclusive evidence is still out, but it seems likely that mTOR inhibition can have antiepileptogenic effects in a subset of TSC patients. It is likely that this subset will be largely defined by age, and we will need to further study the effect of mTOR inhibition in children under 2 years old as a symptomatic and preventative treatment. Small case series suggest that temporary treatment with mTOR inhibition in infants is probably safe showing a similar adverse events profile as in older children. ${ }^{15,16}$ However, age-specific concerns regarding vaccinations and the higher burden of infectious disease in young children cannot yet be fully addressed. 
Interestingly, a report of a case series of 4 infants with TSC-related refractory West syndrome treated with everolimus reported seizure freedom in 2 of $4 .^{17}$

Early or preventative treatment trials should therefore also address the question of treatment duration. Treatment may not be necessary long term for the prevention of epileptogenesis, and potential long-term side effects on growth or immunity in young children are largely unknown. These cannot be fully investigated in controlled trials that normally last a maximum of a few years, but prospective cohort studies will hopefully answer these questions.

\section{Can everolimus prevent intellectual disability and autism in TSC?}

The age of onset of seizures and the time to response to treatment are the most important predictors of cognitive development in children with TSC. ${ }^{18-20}$ Also, the age of seizure onset and severity of autistic features are closely interrelated, suggesting that early and aggressive treatment of seizures can ameliorate other neurocognitive outcomes. ${ }^{21}$

The recommended treatment at this time for young children with TSC and focal seizures or infantile spasms is vigabatrin. ${ }^{10}$ Treatment with vigabatrin soon after seizure onset in infants results in significantly lower risks of intellectual disability and autism, as compared to children treated with a treatment delay. ${ }^{20}$ Treatment with vigabatrin before the onset of seizures may be even more beneficial, and the running EPISTOP and PREVENT studies will hopefully answer this important question. ${ }^{19}$ Since epilepsy is such an important driver of intellectual disability and autism in children with TSC, experts agree that aggressive treatment of early onset epilepsy is warranted. ${ }^{10}$ For now, it is uncertain whether preseizure onset treatment with mTOR inhibition could prevent the development of epilepsy and contribute to better cognitive development through this mechanism. A positive effect of 6 months mTOR inhibition on neurocognition and behavior in children with TSC of 6 years and oldercould not be shown. ${ }^{22}$ There is currently no support for prescribing everolimus to improve behavior or cognition in the absence of intractable epilepsy.

\section{Will a combination of everolimus with other disease-modifying drugs be of additional benefit?}

When mTOR inhibition is discussed in the context of treatment of TSC, this usually refers to mTORC1 inhibition specifically. There are, however, other targets and functions of the TSC proteins that may be affected by mutations in TSC1 or TSC2 and may contribute to the phenotype. For example, TSC1 functions independently of TSC2 by regulating TGF- $\beta$-induced growth arrest and epithelial-to-mesenchymal transition (EMT). ${ }^{23}$ Loss of function of the TSC proteins also affects mTORC2 and AKT activity. The contribution of these cellular processes to the phenotype of TSC patients is not clear, but further elucidation may reveal other potential treatment targets.

\section{Conclusion}

Everolimus has been shown to be of great benefit to TSC patients, both in reducing tumor growth and as a treatment for intractable epilepsy. It has not fully lived up to its promise as a disease-modifying drug, however. At least half of TSC patients with intractable epilepsy do not show a clinically relevant seizure frequency reduction. There is no evidence yet of a positive effect on the cognitive and neuropsychiatric deficits in TSC patients. Further studies into the optimal time window, dosing schedules and possibly combination with other drugs may improve the benefit of everolimus for TSC patients.

\section{Disclosure}

Dr. van Eeghen has provided consultation on an advisory board for Novartis. Dr. de Wit has provided consultation on advisory boards for Novartis and Hoffmann-La Roche. Compensation was paid to Dr. de Wit's institution, the Erasmus MC. The authors report no other conflicts of interest in this work.

\section{References}

1. Tritton T, Bennett B, Brohan E, et al. Health utilities and quality of life in individuals with tuberous sclerosis complex (TSC) who experience epileptic seizures: a web-based survey. Epilepsy Behav. 2019;92:213-220. doi:10.1016/j.yebeh.2018.11.021

2. Bissler JJ, Kingswood JC, Radzikowska E, et al. Everolimus for angiomyolipoma associated with tuberous sclerosis complex or sporadic lymphangioleiomyomatosis (EXIST-2): a multicentre, randomised, double-blind, placebo-controlled trial. Lancet. 2013;381 (9869):817-824. doi:10.1016/S0140-6736(12)61767-X

3. Franz DN, Agricola K, Mays MA, et al. Everolimus for subependymal giant cell astrocytoma: 5-year final analysis. Ann Neurol. 2015;78 (6):929-938. doi:10.1002/ana.24523

4. Abs E, Goorden SM, Schreiber J, et al. TORC1-dependent epilepsy caused by acute biallelic Tsc1 deletion in adult mice. Ann Neurol. 2013;74(4):569-579. doi:10.1002/ana.23943

5. Zeng LH, Xu L, Gutmann DH, Wong M. Rapamycin prevents epilepsy in a mouse model of tuberous sclerosis complex. Ann Neurol. 2008;63 (4):444-453. doi:10.1002/ana.21331

6. Overwater IE, Rietman AB, Bindels-de Heus K, et al. Sirolimus for epilepsy in children with tuberous sclerosis complex: a randomized controlled trial. Neurology. 2016;87(10):1011-1018. doi:10.1212/ WNL.0000000000003077 
7. Li M, Zhou Y, Chen C, et al. Efficacy and safety of mTOR inhibitors (rapamycin and its analogues) for tuberous sclerosis complex: a meta-analysis. Orphanet J Rare Dis. 2019;14(1):39. doi:10.1186/ s13023-019-1012-x

8. French JA, Lawson JA, Yapici Z, et al. Adjunctive everolimus therapy for treatment-resistant focal-onset seizures associated with tuberous sclerosis (EXIST-3): a phase 3, randomised, double-blind, placebo-controlled study. Lancet. 2016;388(10056):2153-2163. doi:10.1016/S0140-6736(16)31419-2

9. Franz DN, Lawson JA, Yapici Z, et al. Everolimus dosing recommendations for tuberous sclerosis complex-associated refractory seizures. Epilepsia. 2018;59(6):1188-1197. doi:10.1111/epi.14085

10. Curatolo P, Nabbout R, Lagae L, et al. Management of epilepsy associated with tuberous sclerosis complex: updated clinical recommendations. Eur J Paediatr Neurol. 2018;22(5):738-748. doi:10.1016/j.ejpn.2018.05.006

11. Curatolo P, Jóźwiak SNabbout R. TSC consensus meeting forSEGA and epilepsy management. management of epilepsy associated with tuberous sclerosis complex (TSC): clinicalrecommendations. Eur J Paediatr Neurol. 2012;16(6): doi:10.1016/j.ejpn.2012.05.004

12. Franz DN, Lawson JA, Yapici Z, et al. Everolimus for treatment-refractory seizures in TSC: extension of a randomized controlled trial. Neurol Clin Pract. 2018;8(5):412-420. doi:10.1212/ CPJ.0000000000000514

13. Cox RL, Calderon de Anda F, Mangoubi T, Yoshii A. Multiple critical periods for rapamycin treatment to correct structural defects in Tsc-1-suppressed brain. Front Mol Neurosci. 2018;11:409. doi:10.3389/fnmol.2018.00409

14. Peters JM, Prohl A, Kapur K, et al. Longitudinal effects of everolimus on white matter diffusion in tuberous sclerosis complex. Pediatr Neurol. 2019;90:24-30. doi:10.1016/j.pediatrneurol.2018.10.005

15. Aw F, Goyer I, Raboisson MJ, Boutin C, Major P, Dahdah N. Accelerated cardiac rhabdomyoma regression with everolimus in infants with tuberous sclerosis complex. Pediatr Cardiol. 2017;38 (2):394-400. doi:10.1007/s00246-016-1528-y
16. Krueger DA, Capal JK, Curatolo P, et al. TSCure research group. Short-term safety of mTOR inhibitors in infants and very young children with tuberous sclerosis complex (TSC): multicentre clinical experience. Eur J Paediatr Neurol. 2018;22(6):1066-1073. doi:10.1016/j.ejpn.2018.06.007

17. Samueli S, Dressler A, Gröppel G, Scholl T, Feucht M. Everolimus in infants with tuberous sclerosis complex-related West syndrome: first results from a single-center prospective observational study. Epilepsia. 2018;59(9):e142-e146. doi:10.1111/epi.14529

18. Overwater IE, Verhaar BJ, Lingsma HF, et al. Interdependence of clinical factors predicting cognition in children with tuberous sclerosis complex. J Neurol. 2017;264(1):161-167. doi:10.1007/s00415016-8335-5

19. Jóźwiak S, Kotulska K, Domańiska-Pakiela D, et al. Antiepileptic treatment before the onset of seizures reduces epilepsy severity and risk of mental retardation in infants with tuberous sclerosis complex. Eur J Paediatr Neurol. 2011;15:424-431. doi:10.1016/j.ejpn.2011. 03.010

20. Bombardieri R, Pinci M, Moavero R, Cerminara C, Curatolo P. Early control of seizures improves long-term outcome in children with tuberous sclerosis complex. Eur J Paediatr Neurol. 2010;14 (2):146-149. doi:10.1016/j.ejpn.2009.03.003

21. van Eeghen AM, Pulsifer MB, Merker VL, et al. Understanding relationships between autism, intelligence, and epilepsy: a cross-disorder approach. Dev Med Child Neurol. 2013;55 (2):146-153. doi:10.1111/dmcn.12044

22. Krueger DA, Sadhwani A, Byars AW, et al. Everolimus for treatment of tuberous sclerosis complex-associated neuropsychiatric disorders. Ann Clin Transl Neurol. 2017;4(12):877-887. doi:10.10 02/acn3.494

23. Thien A, Prentzell MT, Holzwarth B, et al. TSC1 activates TGF$\beta$-Smad2/3 signaling in growth arrest and epithelial-tomesenchymal transition. Dev Cell. 2015;32(5):617-630. doi:10.1016/j.devcel.2015.01.026
Therapeutics and Clinical Risk Management

\section{Publish your work in this journal}

Therapeutics and Clinical Risk Management is an international, peerreviewed journal of clinical therapeutics and risk management, focusing on concise rapid reporting of clinical studies in all therapeutic areas, outcomes, safety, and programs for the effective, safe, and sustained use of medicines. This journal is indexed on PubMed Central, CAS,
EMBase, Scopus and the Elsevier Bibliographic databases. The manuscript management system is completely online and includes a very quick and fair peer-review system, which is all easy to use. Visit http://www.dovepress.com/testimonials.php to read real quotes from published authors. 